\title{
Quality of end-of-life care of advanced cancer patients in mainland China - a retrospective cohort of 441 hospital-death in a public funded comprehensive hospital
}

\author{
Ji Shi Li ${ }^{1}$, Tai-Chung Lam ${ }^{2}$, Hai Man Jing ${ }^{1}$, Xian Chen ${ }^{1}$, Meng Yao Cao ${ }^{1}$, Chun Huang ${ }^{1}$, Li Yang ${ }^{1}$, \\ Zhi Yuan Xu ${ }^{1}$, Yong Jiang ${ }^{1}$, Sha Sha Li ${ }^{1}$, Fang Chen ${ }^{1}$, Ying Han ${ }^{1}$, Yong Sheng Zhang ${ }^{1}$, Ka-On Lam ${ }^{2}$, \\ Anne W. M. Lee ${ }^{2}$
}

${ }^{1}$ Department of Clinical Oncology, The University of Hong Kong - Shenzhen Hospital, Shenzhen, China; ${ }^{2}$ Department of Clinical Oncology, Queen Mary Hospital, The University of Hong Kong, Hong Kong, China

Contributions: (I) Conception and design: JS Li, TC Lam, KO Lam; (II) Administrative support: AWM Lee, HM Jing, X Chen, MY Cao; (III) Provision of study materials or patients: C Huang, L Yang, ZY Xu, Y Jiang, SS Li, F Chen, Y Han, YS Zhang; (IV) Collection and assembly of data: JS Li, C Huang; (V) Data analysis and interpretation: JS Li, TC Lam; (VI) Manuscript writing: All authors; (VII) Final approval of manuscript: All authors.

Correspondence to: Tai-Chung Lam. Department of Clinical Oncology, Queen Mary Hospital, The University of Hong Kong, Hong Kong, China. Email: lamtc03@hku.hk.

\begin{abstract}
Backgrounda Shenzhen is a rapidly growing city in China with a population of over 11 million. The Hong Kong University-Shenzhen Hospital (HKU-SZH) was established in 2012 as a new model of publicly funded health care in mainland China. The clinical oncology center of the HKU-SZH was launched in 2013 which pledged to provide integrated palliative care for advanced cancer patients. This study aims to retrospectively analyze the quality of end-of-life care amongst patients with advanced cancer during their last hospitalization in the HKU-SZH.
\end{abstract}

Methods: Consecutive patients with advanced solid cancer who passed away in the HKU-SZH from March 2013 to February 2016 were analyzed. Clinical information regarding cancer diagnosis, anticancer treatments, and the aggressiveness of the treatment during the last month of life was recorded. The discussions on the Do-Not-Resuscitate (DNR) order with family members were reviewed.

Results: From March 2013 to February 2016, 441 patients with advanced solid cancer passed away in the HKU-SZH. A minority of them $(9.3 \%, 41 / 441)$ received cytotoxic chemotherapy in the last month of life. Younger patients had high odds of receiving chemotherapy in their last month of life (OR 2.6, P=0.006). Those who received chemotherapy in their last month of life showed a trend of higher odds of admission to the intensive care unit (OR 2.94, $\mathrm{P}=0.08)$. The vast majority of family members / care providers $(92.3 \%$, 407/441) consented to the DNR order suggested by oncologists. The rate of DNR acceptance in this cohort was higher than previous reports from mainland China. Within HKU-SZH, the rate was higher in the oncology center than in other departments (OR 5.1, $\mathrm{P}<0.001$ ). The use of chemotherapy in the last month of life did not associated with the acceptance of DNR (OR 1.3, P=0.23).

Conclusions: The integrated oncology service of the new public hospital HKU-SZH achieved a satisfactory level of end-of-life care in patients with advanced cancer. Further studies are warranted to improve the early integration of palliative care service and to investigate the impact of palliative care on costeffectiveness of oncology service.

Keywords: Advanced cancer; palliative care; end of life; chemotherapy; Do-Not-Resuscitate; Hong Kong University-Shenzhen Hospital

Submitted Aug 28, 2019. Accepted for publication Jun 23, 2020.

doi: 10.21037/apm-19-268

View this article at: http://dx.doi.org/10.21037/apm-19-268 


\section{Introduction}

Palliative care is an approach to improve the quality of life for patients and their care-givers facing problems associated with life-threatening illnesses $(1,2)$. A growing body of evidence showed that integration of palliative care into standard oncology care resulted in improvements in quality of life, symptom control, patient and caregiver satisfaction, understanding of illness, quality of end-of-life (EOL) care, survival, and cost of care (3-5).

EOL care is an essential component of palliative care. There are various ways to assess the quality of end-of-life care service. The common indicators used to define overly aggressive palliative care in end-of-life services include (6): new anti-cancer therapies or continuation of treatments very near to death; excessive/unnecessary hospital admissions of advanced cancer patients in emergency rooms or intensive care unit (ICU); low utility of hospice services/ resources or late referral.

In mainland China, hospice services were in severe shortage (7). The majority of patients in cities tended to rely on case oncologists throughout their whole disease trajectory and were inclined to pass away in hospitals (8). Transferal of patients to a primary care unit or an organization with palliative care resources was often rejected by the patients and their families (9). Data of quality of endof-life care services in various mainland cancer centers was still scarce.

Shenzhen city, a rapidly growing urban city in China with a population of approximately 11 million, shared similar problem with other major Chinese cities. In view of the huge shortage of oncology and palliative care service, the oncology center of the HKU-SZH was launched in 2013 which pledged to provide integrated oncologypalliative care service.

The HKU-SZH oncology center receives patient referrals from all other centers in China. Cancer patients might also be admitted to the center through emergency room of HKU-SZH. In the HKU-SZH oncology center, all advanced cancer patients were treated according to department's protocol for palliative care. The palliative care protocol outlined the multidisciplinary approach to tackle various aspects of symptom control, the use of strong opioid for pain control as well as psychosocial care of patients and their caregivers in distress. When patients approached the end-of-life period, the medical and nursing team of the center would initiate structured (EOL) care program in oncology ward.
In order to evaluate the effect of the palliative care program, the current study reviewed the EOL care quality indicators of HKU-SZH cancer center, which included the use of cytotoxic chemotherapy during the last month of life, admissions to the accident and emergency department (A\&E) and ICU in the last month of life, and practice of Do-NotResuscitate (DNR) orders. We present the following article in accordance with the PRISMA reporting checklist (available at http://dx.doi.org/10.21037/apm-19-268).

\section{Methods}

The study included all advanced solid cancer patients who expired at the HKU-SZH from March 2013 to February 2016. The clinical characteristics of patients recorded include, demographics, primary malignancy, date of recurrence or metastasis, death and last admission, last hospitalization through oncology clinics or accident \& emergency department (A\&E), lines of systemic anticancer therapies received, date of the last cycle of cytotoxic chemotherapy, initiation of new systemic anticancer therapies in the EOL period, the decision on DNR orders and the process leading to these, the use of cardiopulmonary resuscitation (CPR) and mechanical ventilation. The study had obtained the approval of HKU-SZH institutional review board (no: 2017-01).

Clinical descriptive data were presented as median and range. The relationships between each of the variables were assessed using the $t$ test, chi-squared test, or Fisher's exact test. The Kaplan-Meier method was used for survival analysis. $\mathrm{P}<0.05$ denoted statistical significance. The IBM@ SPSS@ 24.0 software was used for statistical analysis.

\section{Results}

A total of 441 patients with advanced solid cancer expired in the HKU-SZH during the study period. The most prevalent primary malignancies were lung, liver \& biliary, and colorectal cancer. The median age of patients was 62 years (range: 15-93 years). The average length of last hospitalization was 22.3 days (range: 1-302 days). About half $(52.7 \%, 232 / 441)$ of the cohort was covered by the Shenzhen city medical insurance, in which $90 \%$ of the medical expenses were reimbursed. For the rest, 30-50\% of the expenses were covered by basic medical insurance provided by other provinces which had lower rate of reimbursement.

The median overall survival of the cohort, counted 


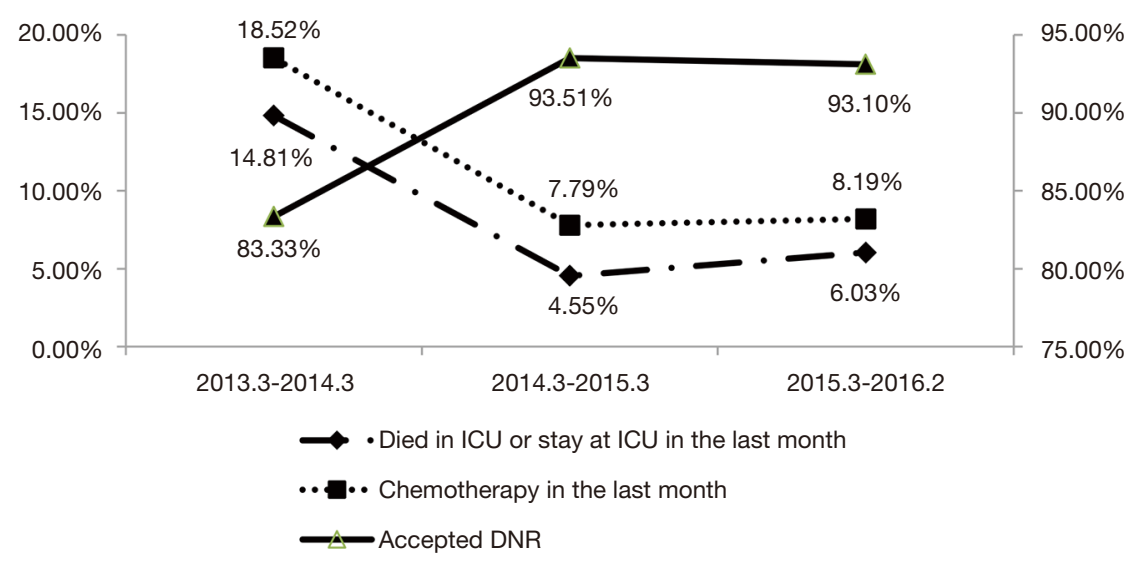

Figure 1 The tendency for the administration of chemotherapy in the last month, acceptance to the DNR order, and admission to the ICU in the last month.

from the time of recurrence or metastasis to death, was 7 months (range: $0-83$ months). Approximately half of the patients $(47.2 \% ; 207 / 441$ patients) had never received any systemic anti-cancer treatment. In this group of patients, the commonest primaries were liver \& biliary, lung, and stomach. The mean age of the group was older than the group who had received chemotherapy [mean age \pm standard deviation (SD) $64.11 \pm 14.57 ; 57.16 \pm 13.94$, $\mathrm{P}<0.001]$.

For chemotherapy use in the end-of-life period, 9.3\% (41/441) underwent chemotherapy in the last month prior to death and $4.8 \%(21 / 441)$ in the last two weeks. Amongst those who underwent chemotherapy in the last month of their lives (41 patients), 68.3\% (28/41 patients) received a new chemotherapy regimen. Patients with ovarian cancer received chemotherapy during the last month more frequently (33.3\%; $7 / 21$ patients) than patients with other types of cancer.

For the hospitalization data, more than half of the patients $(51.5 \% ; 217 / 441$ patients) were admitted through the outpatient department, while $48.5 \%$ (214/441 patients) through the A\&E. In the latter group, 46.7\% (100/214 patients) visited the HKU-SZH for the first time and subsequently expired during this last hospitalization. Notably, 5.2\% patients (23/441) expired in the ICU; $1.4 \%$ (6/441) were transferred to the ICU during the last month but afterwards expired in the general ward. CPR had been performed in $8.4 \%$ of patients (37/441), most frequently in the ICU (34.8\%; 8/23 patients) compared with the wards of clinical oncology department $(5.0 \%, 18 / 359)$ or other departments $(18.6 \%, 11 / 59)$. These differences were statistically significant $(\mathrm{P}=0.000)$.

Vast majority of patients $(92.3 \%$; 407/441) had DNR order in place before death. Within the group, $99.3 \%$ of the DNR order (404/407) were placed after discussion with family members but not with the patients themselves. The rate of DNR acceptance was higher in the clinical oncology center than other departments (OR 5.1, $\mathrm{P}<0.001)$. Despite the DNR order, $1.7 \%$ (7/407) patients still received CPR due to absence of family members when the patient was going to die.

The median time between the date of last admission to the placement of DNR was 9 days (range 0-131 days). The median time of the placement of DNR order before death was 2 days ( $0-89$ days). The interval between DNR placement and death was not significant different for oncology center, ICU and other departments $(\mathrm{P}=0.13)$.

The tendency for the administration of chemotherapy in the last month, consent to the DNR order, and admission to the ICU in the last month are shown in Figure 1. Clinical characteristics in relation to the administration of chemotherapy in the last month and consent to the DNR order are presented in Table 1. There was no correlation between the two factors (OR 1.3, $\mathrm{P}=0.23$ ).

\section{Discussion}

The current cohort of consecutive 441 deceased patients with advanced cancer showed that satisfactory EOL care can be achieved with multidisciplinary, integrative palliative care services in an urban oncology center of mainland China. The overuse of chemotherapy and over-aggressive 
Table 1 Clinical characteristics of patients in relation to the administration of chemotherapy in the last month and consent to the DNR order

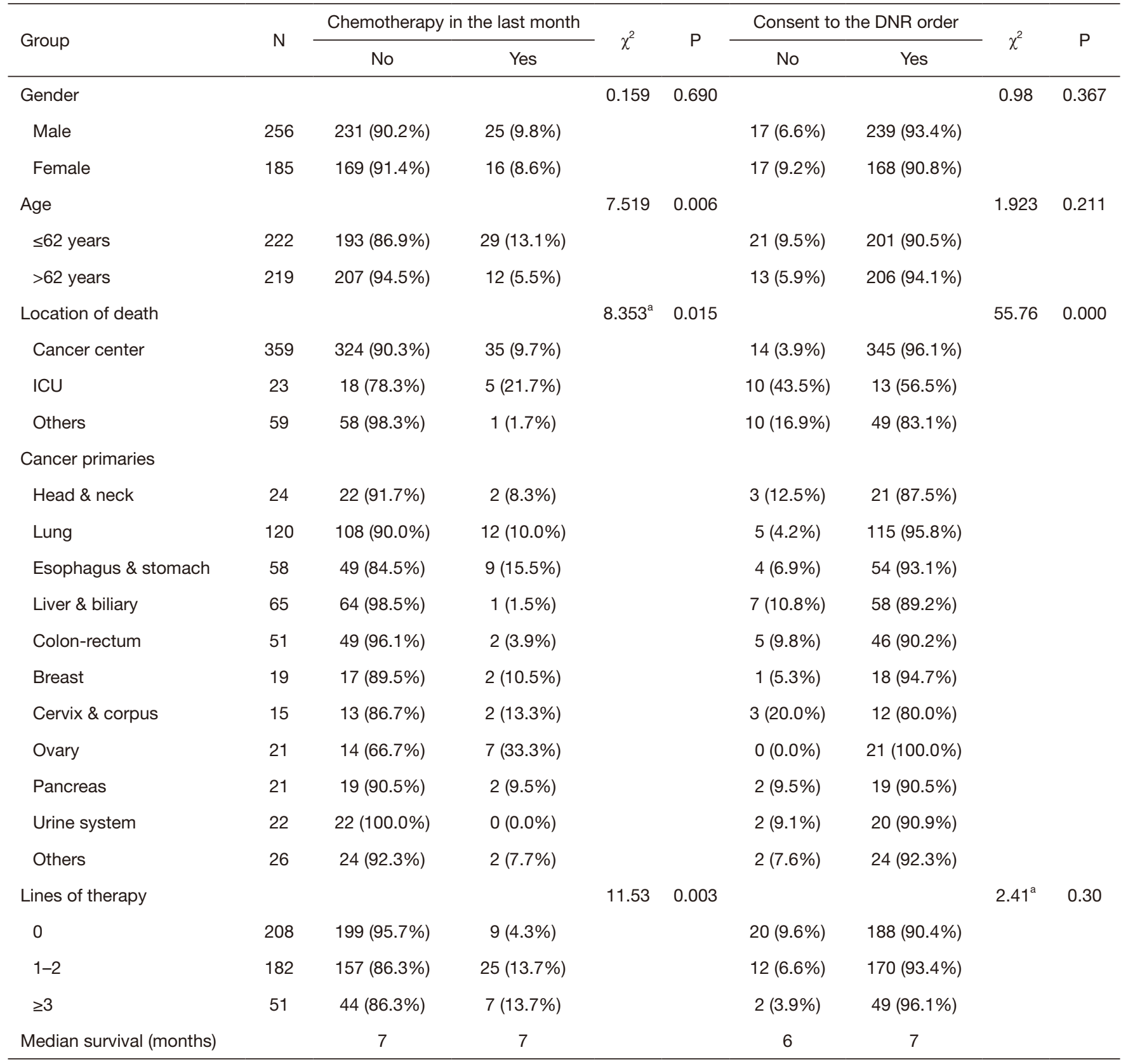

${ }^{\mathrm{a} F i s h e r ' s ~ e x a c t ~ t e s t . ~}$

EOL care (mechanical ventilation / ICU admission) in the last month of life were low at $9.3 \%$ and $9.2 \%$ respectively, and the placement of DNR order was achieved in $92.3 \%$ of all patients.

\section{The use of chemotherapy in the end-of-life period}

The overuse of chemotherapy in the end-of-life period is a common problem world-wide. It had been shown in a prospective study that the administration of chemotherapy in patients with end-stage cancer and a physician-estimated life expectancy of $\leq 6$ months did not improve quality of life. Overuse of chemotherapy may be harmful even in patients with a good performance status (10).

The American Society for Clinical Oncology (ASCO) stated that discontinuation of EOL chemotherapy may 
improve patient care and reduce cost (11). The ASCO recommended not to use cancer-directed therapy in patients with solid tumors who have the following characteristics: poor performance status ( 3 or 4 ), no benefit from prior evidence-based interventions, ineligibility for a clinical trial, and weak evidence supporting the clinical value of further anticancer treatment.

However, according to a survey from African cancer center (12), among all adult patients with reported cancer deaths between 2014 and 2015, 65.9\% received chemotherapy and more than $45 \%$ of patients received chemotherapy in the last 30 days of life. In France (13), among a total of 279,846 hospitalized patients who died from metastatic cancer between January 2010 and December 2013, there were $19.5 \%$ of patients received chemotherapy during the last month before death, and $11.3 \%$ during the last 2 weeks. Compared with university hospitals, patients who died in profit-making clinics/hospital or comprehensive cancer centers were more likely to receive chemotherapy. High-volume centers and hospitals without palliative care units reported greater-than-average rates of chemotherapy near the end of life. A retrospective study investigating 3,350 decedents from six representative hospitals across China from 2010 through 2014 reported that $16.9 \%$ of patients received chemotherapy during the last month of their lives (14).

The phenomenon of over-using chemotherapy might be attributed to a number of reasons. Firstly, oncologists often fail to accurately estimate the survival of individual patients (15). Over-optimistic estimation may lead to continual use of late-line chemotherapy. Secondly, a number of patients did not recognize that chemotherapy was not going to cure their cancer (16). Patients with an understanding of the incurable nature of cancer were less likely to receive chemotherapy in EOL period and associated with increased enrollment to hospice services prior to death (17).

In the present study at the HKU-SZH, 9.3\% of patients received cytotoxic chemotherapy during the last month. This percentage was relatively low compared with other reports in the literature as listed above. For example, one major hospital in Central China reported more than $40 \%$ chemotherapy use in the last 1-3 months of life (18). This favorable outcome may be attributed to several reasons.

Firstly, in the HKU-SZH, we emphasized open and thorough communication of the treatment plan with families (19). In the communication process, we discussed the prognosis and defined the goal of care. We actively offered the option of best supportive care alone among the patients who had very poor prognosis and no evidencebased anti-cancer treatment options. Besides, if the patients and families decided to try a new chemotherapy regimen with limited evidence or efficacy, such decisions would be reviewed by senior oncologists. Once late-line chemotherapy was initiated, patient would be closely monitored for the treatment response and toxicity. The team would promptly stop the treatment if the early results of the regimen was unfavorable.

Another notable finding was that $47.2 \%$ of patients in the current cohort had never received cytotoxic chemotherapy or other systemic anti-cancer therapies. This group of patients were older, and more likely to have primaries of lung, hepatobiliary tract and stomach. Possible reasons for this phenomenon were manifold. It might be related to the lack of effective systemic treatment options for these cancers. This was especially the case before the approval of immunotherapies in China. Many novel targeted agents, which might be less toxic than conventional chemotherapy, were either not available or too expensive in mainland China at the time of the cohort. Besides, integrated palliative care was readily provided by the HKU-SZH team which was a reasonable alternative to the ineffective and toxic systemic treatments.

The present study identified that younger patients and patients who had undergone previous anticancer therapies are more likely to continue chemotherapy in the last month of their life. Furthermore, our data suggest that patients with ovarian cancer are most likely to receive chemotherapy in the last month. These results were consistent with other reports (20). Further studies are needed to evaluate the decision-making process as well as the impact of such an aggressive approach on EOL care and bereavement process of care-givers.

\section{Emergency admission and ICU utilization in the EOL period}

The present study found that $48.5 \%$ of patients with advanced cancer were admitted via the $\mathrm{A} \& \mathrm{E}$ department. In this group of patients, about half of them were visiting HKU-SZH for the first time and subsequently expired during the admission.

The cause of such high rate of A\&E utilization was multifold. The home-care service or family physician system were in infancy in mainland China. The social support of patients at Shenzhen City was also weaker than traditional community as Shenzhen is a city of immigrants. Many 
patients were thousand miles away from their ancestral home and hence was inaccessible to their social supportive network.

Besides, many hospitals in the city were reluctant to admit critically ill late-stage cancer patients while HKUSZH A\&E had performance pledge to accept all patients. The high rate of A\&E utilization was consistent with other reports, including the study conducted at the Seoul National University Hospital that (21) visits to the emergency room by cancer patients during the last month of their life had increased from $22.8 \%$ in 2002 to $74.8 \%$ in 2012 .

For ICU utilization in EOL period, the rate improved from $18 \%$ in the first year of HKU-SZH service to $4-5 \%$ in $2^{\text {nd }}$ to $3^{\text {rd }}$ year. The rate was comparative low compared with other major center in mainland China which reported the rate of around $25 \%$ (18). The improvement was likely contributed to maturation of the clinical teams and improved collaboration amongst different departments. In the current cohort, the use of chemotherapy in the last month was strongly associated with ICU admission in the EOL period. This was consistent with other reports which suggested chemo in EOL period was associated with an increased risk of undergoing CPR, mechanical ventilation, and dying in the $\operatorname{ICU}(22,23)$.

\section{Placement of DNR orders}

In the present study at the HKU-SZH, the overall rate of consent to the DNR order was $>90 \%$. In a similar report at Guangdong Lung Cancer Institute, Wang et al. reported that consent to the DNR order among patients with lung cancer was $74.7 \%$ (24). This disparity may be due to different practices between these two medical institutions. The Guangdong Lung Cancer Institute is a specialized lung cancer center focusing on the anticancer treatment. In contrast, the HKU-SZH Cancer Center is a general comprehensive hospital aiming at provision of integrated palliative care service.

The current cohort at Shenzhen and another palliative care unit from Shanghai report (25) were different from Western reports that most of the DNR order was placed after discussion of health care team with the families, rather than patients themselves. The median interval between the placement of DNR order and death was 2 days, that means most of the DNR decision occurred very close to patients' death. Such a "last minutes" DNR order was common in mainland China. This was probably related to the cultural meaning of "seeing the patient for the last time". Doctors usually would not consider DNR until the impending death was certain and would wait until all the significant family members had "seen" the patients.

The rate of DNR placement differed between departments with HKU-SZH, being higher in the clinical oncology center (96.1\%) than other departments (83.1\%). The team approach of clinical oncology center may contribute to this higher success rate of DNR placement. This highlighted the importance of integrative palliative care team in acute hospital setting and the need of more training on EOL care in other clinical departments.

\section{Limitations}

The major limitation to our study was that the data were retrospectively collected in design. Besides we could not review the minority of patients $(\mathrm{n}<10)$ who were discharged near death, which might have affected the accuracy of the rate of chemotherapy in the last 30 days. We are conducting a prospective longitudinal observational study in a cohort of patients with advanced cancer admitted in the palliative unit in HKU-SZH. We are also in the process of standardizing an integrative palliative care model reimbursement system of Shenzhen.

\section{Conclusions}

The integrative oncology service of the new public hospital HKU-SZH had yielded a satisfactory level of palliative care in advanced cancer patients. Further studies are warranted to investigate the impact of the system on quality of life of patients and their caregivers, as well as the best model to promote early integration of palliative care in mainland China.

\section{Acknowledgments}

The authors are extremely grateful for the generous contributions of the nurses, social workers, medical record administrators and other staff in this project.

Funding: This study was supported by Health and Family Planning Commission of Shenzhen Municipality, which had changed to Shenzhen Municipal Health Commission (Project ID: SZFZ201706).

\section{Footnote}

Provenance and Peer Review: This article was commissioned 
by the editorial office, Annals of Palliative Medicine for the series "Integrating Palliative Medicine in Oncology Care: The Hong Kong Experience". The article has undergone external peer review.

Reporting Checklist: The authors have completed the PRISMA reporting checklist. Available at http://dx.doi. org/10.21037/apm-19-268

Conflicts of Interest: All authors have completed the ICMJE uniform disclosure form (available at http://dx.doi. org/10.21037/apm-19-268). The series "Integrating Palliative Medicine in Oncology Care: The Hong Kong Experience" was commissioned by the editorial office without any funding or sponsorship. TCL served as the unpaid Guest Editor of the series. The authors have no other conflicts of interest to declare.

Ethical Statement: The authors are accountable for all aspects of the work in ensuring that questions related to the accuracy or integrity of any part of the work are appropriately investigated and resolved. The study was conducted in accordance with the Declaration of Helsinki (as revised in 2013). The study had obtained the approval of HKU-SZH institutional review board (no: 2017-01). As it is a retrospective descriptive study, there was no informed consent.

Open Access Statement: This is an Open Access article distributed in accordance with the Creative Commons Attribution-NonCommercial-NoDerivs 4.0 International License (CC BY-NC-ND 4.0), which permits the noncommercial replication and distribution of the article with the strict proviso that no changes or edits are made and the original work is properly cited (including links to both the formal publication through the relevant DOI and the license). See: https://creativecommons.org/licenses/by-nc-nd/4.0/.

\section{References}

1. Hui D, De La Cruz M, Mori M, et al. Concepts and definitions for "supportive care," "best supportive care," "palliative care," and "hospice care" in the published literature, dictionaries, and textbooks. Support Care Cancer 2013;21:659-85.

2. Sepulveda C, Marlin A, Yoshida T, et al. Palliative care: the World Health Organization's global perspective. J Pain Symptom Manage 2002;24:91-6.
3. Kaasa S, Loge JH, Aapro M, et al. Integration of oncology and palliative care: a Lancet Oncology Commission. Lancet Oncol 2018;19:e588-e653.

4. Hui D, Bruera E. Integrating palliative care into the trajectory of cancer care. Nat Rev Clin Oncol 2016;13:159-71.

5. Ferrell BR, Temel JS, Temin S, et al. Integration of Palliative Care Into Standard Oncology Care: American Society of Clinical Oncology Clinical Practice Guideline Update. J Clin Oncol 2017;35:96-112.

6. Earle CC, Park ER, Lai B, et al. Identifying potential indicators of the quality of end-of-life cancer care from administrative data. J Clin Oncol 2003;21:1133-8.

7. Wu Y, Li L, Su H, et al. Hospice and Palliative Care: Development and Challenges in China. Clin J Oncol Nurs 2016;20:E16-9.

8. Wang XS, Di LJ, Reyes-Gibby CC, et al. End-of-life care in urban areas of China: a survey of 60 oncology clinicians. J Pain Symptom Manage 2004;27:125-32.

9. Gu X, Cheng W, Chen M, et al. Timing of referral to inpatient palliative care services for advanced cancer patients and earlier referral predictors in mainland China. Palliat Support Care 2016;14:503-9.

10. Prigerson HG, Bao Y, Shah MA, et al. Chemotherapy Use, Performance Status, and Quality of Life at the End of Life. JAMA Oncol 2015;1:778-84.

11. Schnipper LE, Smith TJ, Raghavan D, et al. American Society of Clinical Oncology identifies five key opportunities to improve care and reduce costs: the top five list for oncology. J Clin Oncol 2012;30:1715-24.

12. Low D, Merkel EC, Menon M, et al. Chemotherapy Use at the End of Life in Uganda. J Glob Oncol 2017;3:711-9.

13. Rochigneux P, Raoul JL, Beaussant $Y$, et al. Use of chemotherapy near the end of life: what factors matter? Ann Oncol 2017;28:809-17.

14. Sheng J, Zhang YX, He XB, et al. Chemotherapy Near the End of Life for Chinese Patients with Solid Malignancies. Oncologist 2017;22:53-60.

15. White N, Reid F, Harris A, et al. A Systematic Review of Predictions of Survival in Palliative Care: How Accurate Are Clinicians and Who Are the Experts? PLoS One 2016;11:e0161407.

16. Weeks JC, Catalano PJ, Cronin A, et al. Patients' expectations about effects of chemotherapy for advanced cancer. N Engl J Med 2012;367:1616-25.

17. Mack JW, Walling A, Dy S, et al. Patient beliefs that chemotherapy may be curative and care received at the end of life among patients with metastatic lung and colorectal 
cancer. Cancer 2015;121:1891-7.

18. Rao J, Fu Q, Wu, Q, et al. Comparison of the Treatments of Patients with Cancer in Their Last 6 Months Between ICU and Cancer Center. Am J Hosp Palliat Care 2016;33:245-51.

19. Chan WL, Lam KO, Siu WK, et al. Chemotherapy at end-of-life: an integration of oncology and palliative team. Support Care Cancer 2016;24:1421-7.

20. Zakhour M, LaBrant L, Rimel BJ, et al. Too much, too late: Aggressive measures and the timing of end of life care discussions in women with gynecologic malignancies. Gynecol Oncol 2015;138:383-7.

21. Choi Y, Keam B, Kim TM, et al. Cancer Treatment near the End-of-Life Becomes More Aggressive: Changes in Trend during 10 Years at a Single Institute. Cancer Res

Cite this article as: Li JS, Lam TC, Jing HM, Chen X, Cao MY, Huang C, Yang L, Xu ZY, Jiang Y, Li SS, Chen F, Han Y, Zhang YS, Lam KO, Lee AWM. Quality of end-of-life care of advanced cancer patients in mainland China-a retrospective cohort of 441 hospital-death in a public funded comprehensive hospital. Ann Palliat Med 2020;9(6):4514-4521. doi: 10.21037/apm$19-268$
Treat 2015;47:555-63.

22. Wright AA, Zhang B, Keating NL, et al. Associations between palliative chemotherapy and adult cancer patients' end of life care and place of death: prospective cohort study. BMJ 2014;348:g1219.

23. Wu CC, Hsu TW, Chang CM, et al. Palliative Chemotherapy Affects Aggressiveness of End-of-Life Care. Oncologist 2016;21:771-7.

24. Wang Z, Li YS, Wu YL. Et al. Do-not-resuscitate orders among advanced-stage Chinese lung cancer patients who died in hospital. Support Care Cancer 2016;24:1763-9.

25. Gu X, Chen M, Liu M, et al. End-of-life decision-making of terminally ill cancer patients in a tertiary cancer center in Shanghai, China. Support Care Cancer 2016;24:2209-15. 